\title{
Umbilical cord length and cord abnormalities in term singleton pregnancy: a review of pregnancy outcome in a tertiary health institution in Nigeria
}

\author{
Charles Njoku,
}

aDepartment of Obstetrics and Gynaecology, University of Calabar, Calabar, Nigeria.

bDepartment of Obstetrics and Gynaecology, University of Calabar Teaching Hospital, Calabar, Nigeria.

Correspondence to Charles Njoku (email: charlesnjokuobinna@gmail.com).

(Submitted: 22 July 2019 - Revised version received: 08 August 2019 - Accepted: 14 August 2019 - Published online: 26 October 2019)

\begin{abstract}
Objective To determine the association of feto-maternal outcomes of term pregnancies with fetal umbilical cord lengths and cord abnormalities in Calabar.

Methods A cross-sectional study of 600 women with singleton pregnancies who delivered either virginally or caesarean section between 37 and 42 completed weeks. Examination of cord was done at delivery for loop round neck, cord length, knots and cord abnormalities. Outcomes recorded include fetal presentation, sex, birth weight, length of newborn and Apgar scores at $1^{\text {st }}$ and $5^{\text {th }}$ min. Also, mode of delivery, labor duration and maternal complications were noted. Cords with abnormalities were sent for histological examination. Data was analyzed using SPSS version 20. Level of significance was set at $P$-value $<0.05$.

Results The mean cord length was $61.07 \pm 14.931 \mathrm{~cm}$, short cords were 23 (7.7\%), long cords were 37 (12.3\%) and 480 (80.0\%) were normal length. Male fetuses had longer cords, mean cord length in the vertex presentations were significantly longer than in breech presentation and increased with increase in birth weight. Abruptio placentae was higher among fetuses with short umbilical cord (17.4\% vs. $0.4 \%)(P$-value $=0.000)$. There was positive correlation between fetal weight and umbilical cord length. Cord coiling index showed a negative correlation with cord length $(r=-0.261 ; P$-value $=0.000)$.

Conclusion Abnormal umbilical cord lengths significantly predispose to obstetric complications but cord abnormalities are rare and does not affect pregnancy outcome. High index of suspicion and careful evaluation of cord may inform and reduce untoward feto-maternal outcome.

Keywords umbilical cord, length, complications, obstetric outcome
\end{abstract}

\section{Introduction}

The umbilical cord (also called the naval string, birth cord or funiculus umbilicus) is a conduit between the fetus and the placenta and indeed the lifeline of the fetus. ${ }^{1}$ It develops from the remnants of the yolk sac and allantois. ${ }^{1}$ The umbilical cord serves very important functions which includes delivering oxygen rich blood through the umbilical vein to the fetus. The umbilical cord also serves as a source of nutrient, including calories, proteins, fats, as well as vitamins to the fetus. ${ }^{2}$ The umbilical cord also transfers waste products and deoxygenated blood away from the fetus to the maternal circulation, where it can be processed and excreted.

The umbilical cord length at term has appreciable variation with extremes ranging from no cord to lengths up to $300 \mathrm{~cm} \cdot{ }^{3,4}$ At birth, the mature normal umbilical cord is between 50 and $60 \mathrm{~cm}$ in length and $37.7 \pm 7.73 \mathrm{~mm}$ in diameter. ${ }^{1,3}$

The umbilical cord can be long or short and there may be as many as 40 spiral twists in the cord as well as false and true knots. ${ }^{3}$ Short cords, defined as cords $<32 \mathrm{~cm}$ long, are seen in $0.4-0.9 \%$ of pregnancies and some studies revealed an incidence of up to 3-10\% of all umbilical cords. ${ }^{1,5-7}$ Long cords, defined as cords length longer than $80 \mathrm{~cm}$ according to some studies or $100 \mathrm{~cm}$ according to others, are seen in $3.7-4 \%$ and $0.5 \%$ of all umbilical cords during pregnancies respectively. ${ }^{1,6}$ Umbilical cord length is one of the factors documented as a definite risk for poor fetal outcome. ${ }^{8}$ There is an association of abnormal cord length with neurological abnormalities and low IQ values. ${ }^{6,9}$ Excessively long or short cord may be the cause of hematoma and thrombosis of cord vessels and the placental surface, thus causing fetal death and or thrombocytopenia. ${ }^{10}$

Causes of differences in cord length are unknown; however, the length of the umbilical cord is thought to reflect the sufficient space in the amniotic cavity for movement and the tensile strength applied to the umbilical cord during fetal movement.

A short cord may be due to reduced fetal activity (such as with twinning; monoamniotic and conjoined), as a primary failure of elongation, and in association with sirenomelia (lack of adequate fetal blood pressure), schisis, anencephaly (lack of hypothalamic hormones), acardia (cardiac output) and adhesions (early amniotic rupture sequence). ${ }^{6}$ It may also be due to oligohydramnios, amnion rupture, uterine structural anomalies as well as substances such as alcohol and beta blockers. ${ }^{5}$ Short cords can interfere with the mechanics of labor and delivery while exhibiting changes in fetal heart rate patterns. ${ }^{6,12}$ This restriction of decent (which is relative to the placental position and insertion) leads to an increase in the incidence of caesarean section, forceps and vacuum extractions. Other complications of excessively short cords include delay in second stage of labor, retained placenta, placental abruption, rupture of umbilical cord, inversion of uterus, birth asphyxia, and cord herniation. ${ }^{3}$

On the other hand, long umbilical cord is directly associated with poor fetal outcome and umbilical cord accidents especially; fetal entanglement and true knots. ${ }^{6}$ Placental changes are associated with long cords suggesting blood flow disruption or 
increased resistance. ${ }^{12}$ Male cords are longer than female cords and term vertex fetuses may have longer lengths than term breech fetuses. ${ }^{6}$ Multigravida cord length may be longer than primagravida cord length. Other complications of excessively long umbilical cords include cord prolapse, torsion, and delivery complications. There are also more cases of fetal distress, fetal anomalies, and respiratory distress. ${ }^{3}$ A multivariate analysis of a small sample of pregnancy reported an association with long cords and intrauterine growth restriction. ${ }^{6}$

The length of the umbilical cord and its position within the amniotic fluid are of great clinical relevance and is associated with a wide range of unfavorable obstetric outcome and this study aims to determine the relationship between length and abnormalities of the umbilical cord and obstetric outcome. Though the pathogenesis of variability of umbilical cord length remains largely unclear, fetal demise or compromise due to cord complication could be a source of depression to the obstetrician, medical community and the mother. In our locality, there is scarcity of data on umbilical cord length and cord abnormalities with relation to feto-maternal outcome. This study would provide information about the length of umbilical cord and cord abnormalities, its association with adverse obstetric outcome in our locality. This will increase awareness, guide obstetricians to pay more attention to, and carefully evaluate umbilical cord length and possible abnormalities to avoid untoward perinatal complications.

\section{Materials and Methods}

This study is a prospective cross-sectional study carried out at the labor ward and theatre of Obstetrics and Gynaecology Department of University of Calabar Teaching Hospital, Calabar. It is a tertiary health facility located in Calabar, South of Nigeria. Ethical approval was obtained from the Research and Ethics Committee of the Hospital. The study was carried out over a 5-months period between February 15 and July 142016. Simple random sampling was used to select participants for the study. The inclusion criteria were primigravida or multigravida with singleton pregnancies who had either vaginal delivery or caesarean section between 37 and 42 completed weeks. Pregnancies complicated by intrauterine fetal death, multiple gestations, congenital malformations of fetus, diabetes, preeclampsia, chorioamnionitis, preterm labor and intrauterine growth restriction were excluded from the study. The sociodemographic characteristics were obtained using pretested questionnaire and this includes initials of clients, hospital number, age, marital status, parity, last menstrual period and gestational age in weeks. Before delivery, fetal presentation, lie and position were determined by abdominal palpation. The mode of delivery was also noted. At delivery the umbilical cord was examined for the following: the presence of any loop around neck, trunk, cord knots (true or false) and any cord abnormalities such as cyst, hematoma, and velamentous insertion.

After the delivery of fetus, the umbilical cord was clamped at two places and cut in between. The length of the umbilical cord was measured from the cut end up to fetal umbilicus and from the other cut end to the placental attachment and the two measurements added to obtain the umbilical cord length. It was measured with flexible tape in centimeters. Other abnormalities of the umbilical cord after delivery were noted clinically.

Lengths of cords were measured and labelled as long $(\geq 80 \mathrm{~cm})$, short $(\leq 32 \mathrm{~cm})$ or normal (between 32 and $80 \mathrm{~cm}$ ).
Thereafter umbilical cords with abnormalities were sent for histological analysis.

Type of insertion on the placenta was also noted. The placenta was examined under running water to remove blood clots and the placental weight measured using a weighing scale and recorded in grams. Fetal parameters that were recorded after the time of delivery include Apgar scores at 1 and 5 min, sex of the newborn, weight of the newborn and length of newborn (by measuring the distance between the crown and the heel). Maternal complications of labor and delivery which includes poor decent of presenting part, prolonged second stage of labor and placental abruption were also noted.

Data obtained were analyzed using the Statistical Package for Social Sciences version 20. Level of significance was set at $P$-value $<0.05$.

\section{Results}

During the study period, there were 1433 deliveries, 600 of the parturient were recruited for the study. Umbilical cord length varied from 20 to $110 \mathrm{~cm}$ with mean length of $61.07 \pm 14.931 \mathrm{~cm}$. Short umbilical cords were 46 (7.7\%), normal cord were 480 $(80.0 \%)$ while long cords were $74(12.3 \%)$. Vaginal delivery was $412(68.7 \%)$ while caesarean section was $188(31.3 \%)$. The mean umbilical cord length was $61.07 \pm 14.93 \mathrm{~cm}$, mean gestational age $38.94 \pm 1.326$ weeks and mean parity $2.21 \pm 1.239$.

Table 1 outlines the socio-demographics characteristics of the parturient. Majority of the parturient were between 30 and 34 years of age $(38.0 \%)$, married $(97.7 \%)$ and women in their first and second pregnancy (para 1 and 2) (66.0\%). Mean umbilical cord length was longer among the age group of $20-24(63.13 \pm 15.69 \mathrm{~cm})$, married women $(61.30 \pm 14.86 \mathrm{~cm})$ and women in their third and fourth pregnancy (para 3 and 4 ) $(63.27 \pm 14.82 \mathrm{~cm})$.

The male fetuses generally had statistically significant longer umbilical cord length than female fetuses (63.74 \pm $15.66 \mathrm{~cm}$ vs. $57.97 \pm 13.44 \mathrm{~cm}$ ) as shown in Table 2. The mean cord length in the vertex presentation group was significantly longer than the breech group $(61.23 \pm 14.95 \mathrm{~cm}$ vs. $54.29 \pm$ $13.25 \mathrm{~cm}$ ). The mean umbilical cord length increased with increase in birth weight and there was statistically significant difference between umbilical cord lengths and birth weight.

Longer umbilical cords were significantly hypocoiled while shorter umbilical cords were hypercoiled. Placental weight group of $0.9-1.0 \mathrm{~kg}$ had the longest mean umbilical cord length and there was statistically significant difference between placenta weight and umbilical cord length $(P$-value $=$ 0.018 ). There was no statistically significant difference between umbilical cord lengths and umbilical cord abnormalities $(P$-value $=0.925)$.

Figure 1 shows the distribution of umbilical cord complications. Most parturient had no umbilical cord complications (82.3\%) and the most common complication was nuchal cord (12.0\%). True knot occurred in $1 \%$, cord round body in $4 \%$ while cord prolapse was $0.7 \%$.

Table 3 shows the correlation between umbilical cord length and feto-maternal outcome. When the umbilical cord length was compared with placental weight using the Pearson's correlation, there was significant positive correlation between placental weight and umbilical cord length $(r=0.212$; $P$-value $=0.000)$. There was also significant positive correlation between umbilical cord length and fetal weight. Umbilical 
Table 1. The feto-placental characteristics in relation to mean cord length

\begin{tabular}{|c|c|c|c|c|}
\hline \multirow[t]{2}{*}{ Variables } & \multirow{2}{*}{$\begin{array}{c}\text { Frequency } \\
(\%)\end{array}$} & $\begin{array}{l}\text { Cord length } \\
(\mathrm{cm})\end{array}$ & \multirow{2}{*}{$\begin{array}{c}\text { Test } \\
\text { statistics }\end{array}$} & \\
\hline & & Mean \pm SD & & \\
\hline \multicolumn{5}{|l|}{ Sex } \\
\hline Male & 161 & $63.74 \pm 15.66$ & 4.8428 & $<0.001$ \\
\hline Female & 139 & $57.97 \pm 13.44$ & & \\
\hline \multicolumn{5}{|l|}{ Lie/Presentation } \\
\hline Vertex & 293 & $61.23 \pm 14.95$ & 6.0171 & $<0.001$ \\
\hline Breech & 7 & $54.29 \pm 13.25$ & & \\
\hline \multicolumn{5}{|l|}{ Fetal weight } \\
\hline$<2.5 \mathrm{~kg}$ & 9 & $60.52 \pm 15.05$ & 1.813 & 0.046 \\
\hline $2.5 \leq 4.0 \mathrm{~kg}$ & 269 & $64.33 \pm 14.57$ & & \\
\hline $\begin{array}{l}4.0 \mathrm{~kg} \text { and } \\
\text { above }\end{array}$ & 22 & $66.41 \pm 12.85$ & & \\
\hline \multicolumn{5}{|c|}{ Length of the neonate } \\
\hline $\begin{array}{l}\text { Below } \\
\text { normal }<45\end{array}$ & 4 & $64.75 \pm 18.998$ & & \\
\hline Normal $45-55$ & 289 & $60.98 \pm 15.012$ & 0.216 & 0.806 \\
\hline $\begin{array}{l}\text { Greater } \\
\text { normal >55 }\end{array}$ & 7 & $63.43 \pm 9.846$ & & \\
\hline \multicolumn{5}{|c|}{ Cord coiling index } \\
\hline $\begin{array}{l}\text { Hypocoiled } \\
<0.17\end{array}$ & $129(43.0)$ & $65.32 \pm 12.61$ & 10.904 & 0.000 \\
\hline $\begin{array}{l}\text { Normal } \\
0.17-0.37\end{array}$ & $165(55.0)$ & $58.18 \pm 15.46$ & & \\
\hline $\begin{array}{l}\text { Hypercoiled } \\
>0.37\end{array}$ & $6(2.0)$ & $49.17 \pm 22.61$ & & \\
\hline \multicolumn{5}{|c|}{ Types of umbilical cord insertion } \\
\hline Centric & $151(50.4)$ & $61.21 \pm 14.775$ & & \\
\hline Eccentric & $103(34.3)$ & $61.58 \pm 15.288$ & 0.241 & 0.869 \\
\hline Marginal & $45(15.0)$ & $59.38 \pm 15.01$ & & \\
\hline Vilamentous & $1(0.15)$ & 63.00 & & \\
\hline \multicolumn{5}{|c|}{ Placental weight (kg) } \\
\hline $0.1-0.2$ & $1(0.3)$ & 64.00 & & \\
\hline $0.3-0.4$ & $24(8.0)$ & $57.25 \pm 15.098$ & & \\
\hline $0.5-0.6$ & $121(40.4)$ & $58.4 \pm 15.837$ & 2.777 & 0.018 \\
\hline $0.7-0.8$ & $129(43.0)$ & $62.96 \pm 13.832$ & & \\
\hline $0.9-1.0$ & $22(7.3)$ & $68.82 \pm 12.764$ & & \\
\hline$>1.0$ & $3(1.0)$ & $59.67 \pm 14.154$ & & \\
\hline \multicolumn{5}{|c|}{ Cord abnormalities } \\
\hline None & $297(99.0)$ & $61.10 \pm 14.973$ & & \\
\hline $\begin{array}{l}\text { Single } \\
\text { umbilical } \\
\text { artery }\end{array}$ & $2(0.7)$ & $57.50 \pm 16.263$ & 0.078 & 0.925 \\
\hline $\begin{array}{l}\text { Umbilical } \\
\text { cord cyst }\end{array}$ & $1(0.3)$ & 58.00 & & \\
\hline
\end{tabular}

Table 2. Correlation between length of umbilical cord with maternal characteristics and obstetric outcome

\begin{tabular}{lcc}
\hline \multirow{2}{*}{ Obstetrics outcome } & Umbilical cord length & \\
\cline { 2 - 2 } & \multicolumn{1}{c}{ Correlation $(\boldsymbol{r})$} & \\
\hline Birth weight & 0.179 & $0.037^{*}$ \\
Gestational age & 0.089 & 0.124 \\
$5^{\text {th }}$ minute Apgar score & -0.022 & 0.703 \\
Length of neonate & 0.066 & 0.255 \\
Maternal age & 0.002 & 0.975 \\
Parity & 0.065 & 0.260 \\
Duration of labor & 0.100 & 0.085 \\
Umbilical cord coiling index & -0.261 & $0.000^{*}$ \\
Placental weight & 0.212 & $0.000^{*}$ \\
\hline *Correlation is significant at $<0.05$ levels (two-tailed). &
\end{tabular}

Umbilical Cord Complications

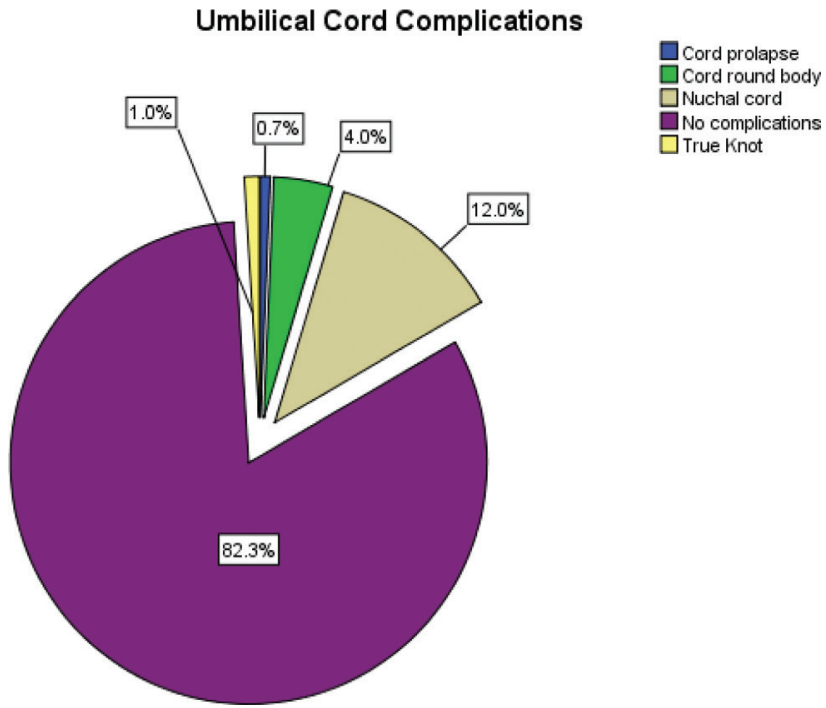

Fig. 1 Umbilical cord complications.

Table 3. The relationship between umbilical cord length and feto-maternal outcomes

\begin{tabular}{lcccc}
\hline Variables & \multicolumn{2}{c}{ Feto-maternal outcome } & Chi-square & $\boldsymbol{P}$-value \\
\hline $\begin{array}{l}\mathbf{1}^{\text {st }} \text { minute } \\
\text { Apgar }\end{array}$ & $<7$ & $\mathbf{2 7}$ & & \\
$\quad$ Short cord & $2(8.6)$ & $21(91.3)$ & 0.60 & 0.752 \\
Long & $8(21.6)$ & $29(78.4)$ & 1.21 & 0.271 \\
$\quad$ Normal & $35(14.6)$ & $205(85.4)$ & Referenced & \\
$\mathbf{5}^{\text {th }}$ minute & $<7$ & $\geq 7$ & & \\
$\begin{array}{l}\text { Apgar } \\
\text { Short cord }\end{array}$ & $2(8.6)$ & $21(91.3)$ & 0.30 & 0.639 \\
$\quad$ Long & $3(8.1)$ & $34(91.9)$ & 0.29 & 0.483 \\
$\quad$ Normal & $14(5.8)$ & $226(94.2)$ & Referenced & \\
$\begin{array}{l}\text { Delayed } \mathbf{2}^{\text {nd }} \\
\text { stage }\end{array}$ & Yes & No & & \\
\hline
\end{tabular}

(Continued) 
Table 3. The relationship between umbilical cord length and feto-maternal outcomes-Continued

\begin{tabular}{|c|c|c|c|c|}
\hline \multirow{2}{*}{$\begin{array}{l}\text { Variables } \\
\text { Short cord }\end{array}$} & \multicolumn{2}{|c|}{ Feto-maternal outcome } & \multirow{2}{*}{$\begin{array}{c}\text { Chi-square } \\
3.54\end{array}$} & \multirow{2}{*}{$\begin{array}{c}\boldsymbol{p} \text {-Value } \\
0.117\end{array}$} \\
\hline & $2(8.7)$ & $21(91.3)$ & & \\
\hline Long & $1(2.7)$ & $36(97.3)$ & 0.06 & 0.581 \\
\hline Normal & $5(2.1)$ & $235(97.9)$ & Referenced & \\
\hline $\begin{array}{l}\text { Abruptio } \\
\text { placentae }\end{array}$ & Yes & No & & \\
\hline Short cord & $4(17.4)$ & 19 (82.6) & 32.42 & 0.000 \\
\hline Long & $1(2.7)$ & $36(97.3)$ & 2.34 & 0.249 \\
\hline Normal & $1(0.4)$ & $239(99.6)$ & Referenced & \\
\hline $\begin{array}{l}\text { Low birth } \\
\text { weight } \\
(<2.5 \mathrm{~cm})\end{array}$ & Yes & No & & \\
\hline Short cord & $2(8.7)$ & $21(91.3)$ & 2.12 & 0.181 \\
\hline Long & $1(2.7)$ & $36(97.3)$ & 0.01 & 1.000 \\
\hline Normal & $7(2.9)$ & $233(97.1)$ & Referenced & \\
\hline $\begin{array}{l}\text { Macrosomia } \\
(>4 \mathrm{~kg})\end{array}$ & Yes & No & & \\
\hline Short cord & $1(4.3)$ & $22(95.7)$ & 0.04 & 1.000 \\
\hline Long & $3(8.1)$ & 34 (91.9) & 0.08 & 0.968 \\
\hline Normal & $19(7.9)$ & $221(92.1)$ & Referenced & \\
\hline Cord round neck & Yes & No & & \\
\hline Short cord & $0(0.00)$ & $23(100)$ & 2.88 & 0.088 \\
\hline Long & $9(24.3)$ & $28(75.7)$ & 4.85 & 0.028 \\
\hline Normal & $27(11.3)$ & $213(88.7)$ & Referenced & \\
\hline $\begin{array}{l}\text { Breech } \\
\text { presentation }\end{array}$ & Yes & No & & \\
\hline Short cord & $2(8.7)$ & $21(91.3)$ & 4.65 & 0.031 \\
\hline Long & $1(2.7)$ & $36(97.3)$ & 0.19 & 0.514 \\
\hline Normal & $4(1.7)$ & $236(98.3)$ & Referenced & \\
\hline
\end{tabular}

Table 4. The maternal characteristics in relation to mean cord length of the study population

\begin{tabular}{lcc}
\hline Variables & Frequency (\%) & Cord length (cm) \\
\cline { 3 - 3 } Age (years) & & Mean \pm SD \\
14-19 & $11(3.7)$ & $58.64 \pm 23.61$ \\
$20-24$ & $30(10.0)$ & $63.13 \pm 15.69$ \\
$25-29$ & $97(32.3)$ & $60.47 \pm 14.57$ \\
$30-34$ & $114(38.0)$ & $61.24 \pm 14.93$ \\
35 and above & $48(16.0)$ & $61.13 \pm 13.17$ \\
Marital status & & \\
Married & $293(97.7)$ & $61.30 \pm 14.86$ \\
Single & $7(2.3)$ & $51.14 \pm 15.65$ \\
Parity & & \\
$1-2$ & $198(66.0)$ & $60.20 \pm 15.09$ \\
$3-4$ & $86(28.7)$ & $63.27 \pm 14.82$ \\
5 and above & $16(5.3)$ & $59.94 \pm 13.03$ \\
\hline
\end{tabular}

cord coiling index showed a significant negative correlation with umbilical cord length $(r=-0.261 ; P$-value $=0.000)$.

Abruptio placentae was significantly higher among fetuses with short umbilical cord than normal umbilical cord length ( $17.4 \%$ vs. $0.4 \%)$ and this difference was statistically significant $(P$-value $=0.000)$. Cord round neck was significantly higher among long umbilical cord than the normal umbilical cord length control $(P$-value $=0.036)$.

\section{Discussion}

Several studies concerning umbilical cord length at term showed that umbilical cord length varies from no cord to lengths up to $300 \mathrm{~cm}$ and mature umbilical cord is between 50 and $60 \mathrm{~cm}$ in length. ${ }^{1,2,4}$ In this study the mean umbilical cord length was $61.07 \mathrm{~cm}$ and ranged from 20 to $110 \mathrm{~cm}$. This study is comparable with the findings in Sudan where the mean cord length was $60.5 \mathrm{~cm}^{13}$ and Agwu et al. ${ }^{14}$ in Abakaliki, Nigeria where the mean cord length was $57 \mathrm{~cm}$ and ranged from 22 to $124 \mathrm{~cm}$. However, this was higher than $52.7 \mathrm{~cm}$ reported in Ilorin by Adesina et al. ${ }^{15}$ This showed that human neonates exhibit wider variations in terms of the length of their umbilical cord as earlier documented by Jaya et al. ${ }^{16}$ and Stefos et al. ${ }^{17}$ respectively. The reason for the difference in the mean values of umbilical cord length obtained in these studies is not very clear but may be because umbilical cord length is influenced by environmental and genetic factors. ${ }^{16}$ Although it is not fully understood what controls cord length, various authors correlate cord length with fetal activity and movement. ${ }^{18}$ It is suggested that sufficient space in the amniotic cavity for movement and the tensile force applied to the umbilical cord during fetal movements are two main factors that determine cord length. However, more recent studies using animal models have argued against the "stretch hypothesis," stating that the umbilical cord continues to grow throughout pregnancy in an almost linear fashion. . $^{5,15}$

The incidence of short cords in this study was $7.7 \%$ of all deliveries is similar to the incidence of $5.9 \%$ in the study by Balkawade and Shinde ${ }^{3}$ and $7.2 \%$ by Adesina et al. ${ }^{15}$ This finding is also similar to other reported incidence of short cords which ranged from $2 \%$ to $10 \%{ }^{13,14,19}$ The incidence of $7.7 \%$ in this study is however higher than $0.7 \%$ reported in Abakaliki, Nigeria. ${ }^{14}$ The marked difference in the reported low prevalence of short cord in that study may have been influenced by the low cut off of $<32 \mathrm{~cm}$ used in the definition of short umbilical cord.

In this present study, the incidence of long umbilical cord was $12.3 \%$ which is higher than $7 \%$ by Agwu et al. ${ }^{14}$ and $9.3 \%$ by Adesina et al. ${ }^{15}$ The significance of long umbilical cords resides in the fact that they may be directly associated with poor fetal outcome and umbilical cord accidents such as fetal entanglement, knot formation (multiple) and torsion.

This study showed that the male fetuses had statistically significant longer umbilical cord length than the female fetuses and there was a significant positive correlation between the sex of neonate and umbilical cord length. This may be explained by the fact that male fetuses normally weigh more than their female counterparts and also by the fact that length of umbilical correlates significantly with birth weight. This is consistent with the findings of Krakowiak et al. ${ }^{5}$ who demonstrated that female infants had shorter cords than male infants.

In this present study, the mean umbilical cord length increased with increase in birth weight and umbilical cord 
length was positively correlated with birth weight. Fetuses with longer umbilical cord were likely to have normal birth weight or to be macrosomic. This could be explained by the fact that as the fetus grows the umbilical cord also increases in length. Agboola ${ }^{20}$ also reported a significant positive correlation between cord length and fetal weight. Wu et al. ${ }^{21}$ in their series using stepwise logistic regression for multivariate analysis of the relationship between umbilical cord length and obstetric outcome found a statistically significant relationship between umbilical cord length and birth weight.

Concerning umbilical cord index, $43 \%$ were hypocoiled, $55 \%$ normocoiled and $2 \%$ hypercoiled. Umbilical cord coiling index showed a significant negative correlation with umbilical cord length which means that with increase in umbilical cord length, the coiling index decreases.

Abnormal coiling (hypo-coiling and hyper-coiling) is known to have chronic (growth retardation) and acute (fetal intolerance to labor and fetal demise) effects on fetal wellbeing. ${ }^{22,23}$ The vessels of the umbilical cord are prone to torsion, compression, tension, and subsequent interruption of the blood flow. This risk is minimized by their helical disposition. It is possible that the coiled umbilical cord has elastic properties that enable it to resist external forces that might compromise the umbilical vascular flow. It may be that, the coiled umbilical cord acts like a semi-erectile organ that is more resistant to snarling torsion, stretch, and compression than the non-coiled one. Hypercoiled cords often have more thrombi in placental surface veins because the flow is more sluggish, and when coiling becomes excessive, the fetus can strangle due to decreased circulation in the cord vessels. ${ }^{24,25}$ Ercal et al. ${ }^{23}$ when comparing neonates with hypocoiled and normocoiled found a higher incidence of meconium staining, interventional delivery, Apgar scores, fetal blood $\mathrm{pH}$ and intrapartum fetal heart rate disturbance in neonates with hypocoiled cords and concluded that umbilical cord index has a strong relationship with perinatal outcome. Thus, detection of an abnormal coiling index can lead to identification of fetuses at risk which need special care to improve perinatal outcome.

There was statistically significant difference between umbilical cord length and placenta weight in this study. The placental weight showed significant positive correlation with umbilical cord length which means that umbilical cord length increases with increase in placental weight. It then implies that, factors which directly affect the weight of the placenta will indirectly affect the length of the umbilical cord. Such factors include nutrition, maternal anemia, altitude, hypertension, maternal diabetes mellitus and other chronic medical illness.

An abnormal placental cord insertion site has been associated with a number of complications of pregnancy that may result from compression or rupture of poorly supported umbilical vessels. ${ }^{1}$ Intrapartum hemorrhage, fetal bradycardia, stillbirth, intrauterine growth restriction and preterm labor have all been linked to velamentous and to a lesser extent, marginal cord insertions. ${ }^{1,26}$ In this present study, there was only a single reported case of velamentous umbilical cord insertion and there was no adverse maternal, fetal or perinatal outcome associated with it. In a study conducted by Adesina et al., ${ }^{15}$ velamentous cord insertions occurred in $1.1 \%$ and $0.9 \%$ respectively of singleton pregnancies.
Several articles concerning umbilical cord length and feto-maternal outcome have been published in the past with conflicting reports. . $, 614,21_{\text {Various reports have demonstrated }}$ that a short umbilical cord was associated with birth asphyxia, abruptio placentae, breech presentation and prolonged second stage of labor. Krakowiak et al..$^{5}$ in their study reported an increase in hypoxic-ischemic encephalopathy, fetal distress, and infant death and low birth weight and a twofold increase in risk of death among term infants born with short cords. On the contrary, a long umbilical cord was frequently associated with cord accidents and fetal distress. In this study, only abruptio placentae and breech presentation were significantly higher among fetuses with short umbilical cord than normal umbilical cord length control. Also, only cord round neck was significantly higher among long umbilical cord than the normal umbilical cord length control. Low birth weight, macrosomia and delayed second stage of labor were not significantly different among long and short umbilical cord compared with normal cord length control. This study also did not found an increase in intrapartum fetal distress and birth asphyxia with length of umbilical cord. This finding is similar to the study in Taiwan where multivariate analysis of the relationship between umbilical cord length and obstetric outcome found no association between umbilical cord length and antepartum and intrapartum fetal wellbeing. ${ }^{21}$ However, this is in contrast to the study where Agwu et al. ${ }^{14}$ found an increase intrapartum fetal distress and birth asphyxia in the long cord arm group. The difference with study may be related to the difference in patients' selection for the study, intrapartum monitoring and caesarean sections rates in different studies.

Umbilical cord abnormality was $1 \%$ of total deliveries. There was no significant association between varying umbilical cord lengths and umbilical cord abnormalities. This may be due to rarity of these abnormalities as it occurs in $1 \%$ of live birth from other studies also. ${ }^{14,15,27}$ Another study also reported an incidence of $0.2 \%$. Adesina et al. ${ }^{15}$ noted that single umbilical artery is associated with low birth weight babies and preterm deliveries. Neonates with single artery have increased risks of congenital and chromosomal abnormalities as well as adverse perinatal outcome. ${ }^{27}$ The two neonates with single umbilical cord had moderate birth asphyxia but made good recovery in the perinatal period and there were no obvious congenital anomalies among them.

This study did not utilize the intrapartum evaluation with Doppler ultrasound to possibly determine cord length and abnormalities as to reduce feto-maternal complications during delivery. Further research is therefore needed to determine the umbilical cord characteristics using high definition Doppler ultrasound and relationship with obstetric outcome.

\section{Conclusion}

The study showed that the length of umbilical cord varied from 20 to $110 \mathrm{~cm}$ with mean of $61.07 \pm 14.931 \mathrm{~cm}$. Abruptio placentae and breech presentation were significantly higher among fetuses with short umbilical cord than normal and cord round neck was significantly higher among long umbilical cord than the normal cord length. Cord abnormalities were very rare and there were no significant association between umbilical cord lengths and umbilical cord abnormalities from this study. Appropriate examination and documentation of umbilical cord length and abnormalities is necessary. This will 
provide more information on fetal well-being, neonatal outcome and basis for further studies. Ante partum or intrapartum obstetric ultrasound scan for possible abnormal cord lengths and cord abnormalities may reduce untoward pregnancy outcome.

\section{Conflicts of Interest}

None.

\section{References}

1. Kulkarni ML, Matadh PS, Ashok C, Pradeep N, Avinash T, Kulkarni AM. Absence of Wharton's jelly around the umbilical arteries. Indian J Pediatr 2007;74:787-789.

2. Pathak S, Hook E, Hackett G, Murdoch E, Sebire NJ, Jessop F, et al. Cord coiling, umbilical cord insertion and placental shape in an unselected cohort delivering at term: relationship with common obstetric outcomes. Placenta. 2010;31:963-968.

3. Balkawade NU, Shinde MA. Study of length of umbilical cord and fetal outcome : a study of 1,000 deliveries. J Obstet Gynecol India. 2012;62: 520-525.

4. Yadav B, Kurdukar, DV, Darade RV, Mahadar NA. Correlation of umbilical cord length and foetal outcome. J Evol Meical Dent Sci. 2013;2:412-417.

5. Krakowiak P, Smith EN, de Bruyn G, Lydon-Rochelle MT. Risk factors and outcomes associated with a short umbilical cord. Obstet Gynecol. 2004:103:119-127.

6. Collins JH. Umbilical cord accidents. BMC Pregnancy Childbirth. 2012;12:A7.

7. LaMonica GE, Wilson ML, Fullilove AM, Rayburn WE. Minimum cord length that allows spontaneous vaginal delivery. J Reprod Med. 2008;53: 217-219.

8. Hershkovitz R, Silberstein T, Sheiner E, Shoham-Vardi I, Holcberg G, Katz M, et al. Risk factors associated with true knots of the umbilical cord. Eur J Obstet Gynecol Reprod Biol. 2001;98:36-39.

9. Sørnes T. Umbilical cord knots. Acta Obstet Gynecol Scand. 2000;79: 157-159.

10. Sangwan V, Nanda S, Sangwan M, Malik R, Yadav M. Cord complications: associated risk factors and perinatal outcome. Open J Obstet Gynecol. 2011;1:174-177.

11. Beall MH, Ross MG. Umbilical cord complications. Medscape. 2014.

12. Collins $\mathrm{CL}$, Collins $\mathrm{CL}$, Collins CC. Umbilical cord accidents. Pregnancy Inst. 2010:1-84.

13. Ahmed M, Nuggedalla A. A preliminary study on the morphological variations in the umbilical cord Sundanese. Time J Med Sci Rep Res. 2013;1:10-15.

14. Agwu UM, Umeora OUJ, Ogbonnaya LU, lyare FE, Obuna JA, Umahi VE, et al. Fetal umbilical cord length and associated intrapatum complications in a tertiary institution, Southeast Nigeria. Ebonyi Med J. 2010;9:112-119.
15. Adesina KT, Ogunlaja OO, Aboyeji AP, Olarinoye OA, Adeniran AS, Fawole AA, et al. Umbilical cord parameters in llorin: correlates and foetal outcome. East Afr Med J. 2014;19:274-280.

16. Jaya DS, Kumar NS, Bai LS. Anthropometric indices, cord length and placental weight in newborns. Indian Pediatr. 1995;32:1183-1188.

17. Stefos T, Sotiriadis A, Vasilios D, Tsirkas P, Korkontzelos I, Avgoustatos F, et al. Umbilical cord length and parity - the Greek experience. Eur J Obstet Gynecol Reprod Biol. 2003;107:41-44.

18. Bimpong S. Qualitative evaluation of umbilical cord and placental indices and pregnancy outcome (master's thesis). Kwame Nkrumah University of Science and Technology, Kumasi, 2012.

19. Georgiadis L, Keski-Nisula L, Georgiadis S, Räisänen S, Harju M, Heinonen S Short umbilical cord - a risk factor for placental abruption? Placenta. 2014;35:275-280

20. Agboola A. Correlates of human umbilical cord length. Int J Gynaecol Obstet. 1978-1979;16:238-239.

21. Wu JF, Chang SY, Hsu TY, Hsieh CH, Kung FT, Hwang FR, et al. Multivariate analysis of the relationship between umbilical cord length and outcome. Chang Gung Med J. 1996;19:247-252.

22. Chitra T, Sushanth YS, Raghavan S. Umbilical coiling index as a marker of perinatal outcome: an analytical study. Obstet Gynecol Int. 2012;2012:213689.

23. Ercal T, Lacin S, Altunyurt S, Saygili U, Cinar O, Mumcu A. Umbilical coiling index: is it a marker for the foetus at risk? Br J Clin Pract. 1996;50:254-256.

24. Kashanian M, Akbarian A, Kouhpayehzadeh J. The umbilical coiling index and adverse perinatal outcome. Int J Gynaecol Obstet. 2006;95:8-13.

25. de Laat MW, Franx A, van Alderen ED, Nikkels PG, Visser GH. The umbilical coiling index, a review of the literature. J Matern Fetal Neonatal Med. 2005;17:93-100.

26. Appia PK. Relationship between the morphology of the placenta, umbilical cord and perinatal outcome (master's thesis). Kwame Nkrumah University of Science and Technology, 2009.

27. Martínez-Frías ML, Bermejo-Sánchez E, Rodríguez-Pinilla E, Prieto-Merino D, Grupo de Periférico del ECEMC. [Characteristics of neonates with and without a single umbilical artery. Analysis of two consecutive series of neonates with and without congenital defects]. Ann Pediatr (Barc). 2006;65:541-550. 